\title{
Examining Teachers' Behavioral Intention to Use E-learning in Teaching of Mathematics: An Extended TAM Model
}

\author{
Mailizar Mailizar \\ Mathematics Education Department, Universitas Syiah Kuala, Indonesia \\ ORCID: 0000-0003-4084-311X \\ Abdulsalam Almanthari \\ University of Technology and Applied Sciences - Ibri, Oman \\ ORCID: 0000-0001-6861-5974 \\ Suci Maulina \\ Realistic Mathematics Education Research Centre, Universitas Syiah Kuala, Indonesia \\ ORCID: 0000-0001-9217-0530
}

Received: 8 Jul 2020

Accepted: 10 Dec 2020

\begin{abstract}
The aim of this study was to examine factors that influenced experienced teachers' intention to use Elearning in their teaching of mathematics. Data were collected using a questionnaire from 161 secondary school mathematics teachers who completed a six-month in-service online training provided by the Indonesian Ministry of Education. The Technology Acceptance Model (TAM) was used as the framework while E-learning experience was included as an additional construct. An extended TAM model was proposed and tested in this study. It consisted of five constructs, namely: intention to use, perceived usefulness, perceived ease of use, attitude toward using, and experience. Data were analyzed using Structural Equation Modelling with SMARTPLS 3.0. The findings showed that attitude toward E-learning use and E-learning experience were the two most significant constructs in predicting E-learning use. Contrary to previous studies, perceived ease of use and perceived usefulness were non-significant factors for the prediction of the behavioral intention. Implications for future research and practices are discussed.
\end{abstract}

Keywords: behavioral intention, teachers' intention to use e-learning, extended TAM model, teachers' elearning experience, e-learning in mathematics classroom

\section{INTRODUCTION}

In Indonesia, 45.5 million school students and 3.1 million teachers are dependent on online teaching and learning due to school closures during COVID-19 pandemic (Mailizar, Almanthari, Maulina, \& Bruce, 2020). As a result, education in the country has changed dramatically with the rising need of E-learning adoption. According to Cigdem and Topcu (2015), institutions that expect their teaching staff to use E-learning should consider their behavioral intention to use E-learning systems. The Technology Acceptance Model (TAM) (Davis, 1986) is the mostly used model in studies of users' acceptance of technologies (Cigdem \& Topcu, 2015). The main aim of the model is to describe users' behavior toward the adoption of technology (Chang, Hajiyev, \& Su, 2017).

TAM has been widely used in studies that investigate e-learning. Although the model has been scrutinized, validated and praised for its contribution to science, it has been argued that it has some limitations. 
Theoretically, some researchers have argued that the popularity of TAM is linked to its simplicity which does not address the complexity associated with e-learning use in institutional contexts (Ajibade, 2018; Chuttur, 2009). However, the core of the theory remains the same in most studies and the majority of changes are made to the external variables discussed in the theory or adding elements as part of perceived usefulness and perceived ease of use. For example, Venkatesh and Davis (2000) proposed TAM 2 with additional variables with additional constructs. Some of the constructs broke PU into several components such as job relevance, result demonstrability, etc. Another limitation of TAM is that studies that follow it depend mainly on self-reported data without use of data generated from systems about their use (Chuttur, 2009). Ajibade (2018) argues that TAM assumes that more use is better without placing adequate emphasis on impact of system use on performance. Ajibade (2018) also argues that TAM is more appropriate for personal use than institutional use due its lack of focus on the impact on policies, management, expectations and workplace factors. However, TAM has been adapted differently to suit the specific requirements for specific institutions and contexts.

Previous studies have extended the TAM model, resulting in various external factors of TAM (Abdullah \& Ward, 2016; Martin, 2012). Abdullah and Ward (2016) conducted a meta-analysis study and found that subjective norm, experience, perceived enjoyment, computer anxiety and self-efficacy were the most commonly used external factors for TAM. According to Abdullah and Ward (2016), experience is one of the most commonly used external factors in E-learning acceptance studies.

As discussed earlier, TAM was adapted differently by different researchers based on several factors including their needs, contexts, research focus and conceptualization of the TAM. In this study, experience was included due to the need to examine teachers' prior e-learning experience on their perceived usefulness, perceived ease of use and behavioral intention. As discussed in this study, there is dearth of research in this area and investigating it contributes to our understanding of its importance and impact.

The previous studies that used experience as an external factor of TAM looked at different types of E-learning users namely, employees (Lee, Hsieh, \& Chen, 2013; Lee, Hsieh, \& Ma, 2011; Purnomo \& Lee, 2013), students (Abbad, Morris, \& De Nahlik, 2009; Lau \& Woods, 2008; Williams \& Williams, 2010), student and educators (Martin, 2012), and teachers (De Smet, Bourgonjon, De Wever, Schellens, \& Valcke, 2012).

In terms of teachers' experience in E-learning, many teachers in Indonesia have experiences of using Elearning for their professional development (PD). The Ministry of Education and Culture offers a six-month online PD course for teachers in 42 higher education institutions throughout the country (Mailizar, Samingan, Rusman, Huda, \& Yulisman, 2020). This course, consisting of general pedagogy, subject-specific pedagogy, and content area, is a 12-credit raining course required for teachers in order to be awarded a teaching certificate.

However, to the best of our knowledge, no empirical studies were conducted about secondary school teachers' behavioral intention to use E-learning in teaching, particularly that focus on secondary mathematics school teachers who have experience in using E-learning for their PD (hereafter, experienced teachers). Therefore, in this study, teachers' E-learning experience during their PD was used as an external factor of TAM model. Consequently, using TAM as a theoretical foundation and employing Structural Equation Modelling (SEM), this study aims to examine factors affecting experienced teachers' behavioral intentions to use E-learning in their teaching of mathematics.

\section{THEORY AND RELATED LITERATURE}

Several models, such as Technology Acceptance Model (TAM) (Davis, 1986), Theory of Planned Behavior (TPB) (Ajzen, 1991), and Unified Theory of Acceptance and Use of Technology (Venkatesh, Morris, Davis, \& Davis, 2003) have been developed and proposed to investigate users' intention to use emerging technology. TAM is one of the most widely used models to investigate and predict users' technology acceptance. 


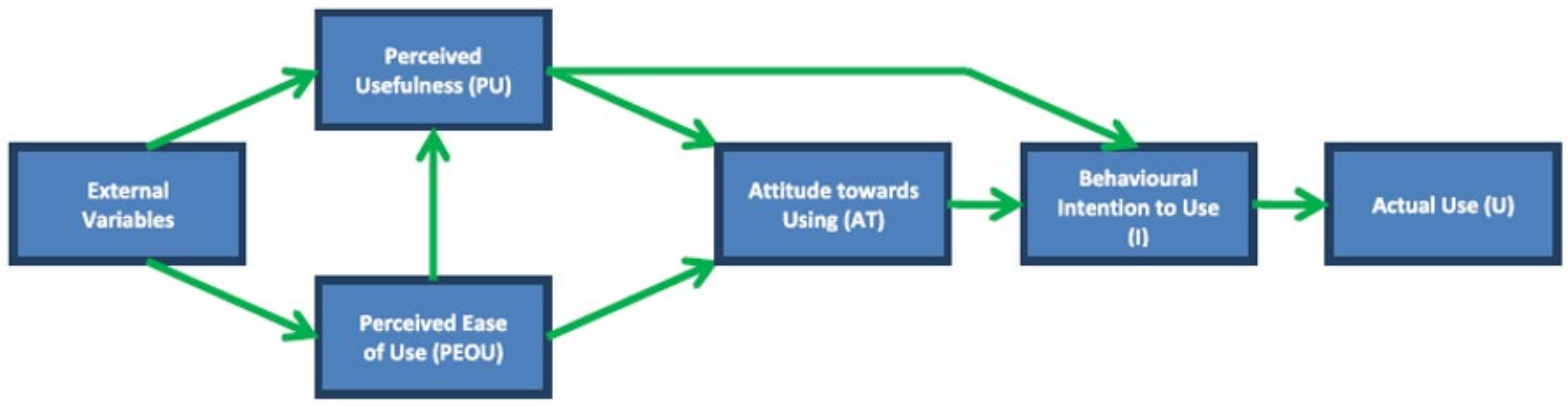

Figure 1. Technology acceptance model (Davis, 1986)

\section{Technology Acceptance Model}

TAM is based on the Theory of Reasoned Action proposed by Fishbein and Ajzen (1975). According to Fishbein and Ajzen, behaviour is determined by attitude and subjective norm. Attitude refers to the positive or negative feelings about the behaviour and the subjective norm refers to a person's circle of important people and their acceptance of performing the behaviour.

According to Davis (1996), TAM (Figure 1) is a framework used to investigate how and when users adopt emerging technology. TAM has been proved efficient in explaining users' behavior to use computing technology (Teo, 2010). This model shows the relationship among perceived ease of use (PEU), perceived usefulness (PU), attitude toward use (AT), and intention to use technology (BI).

According to Davis (1989), behavioral intention is affected by attitude toward use. It is also directly and indirectly affected by perceived ease of use and perceived usefulness. Furthermore, perceived ease of use has a direct effect on perceived usefulness, yet the reverse is not true.

Intention to use has a close link with actual behavior (Kiraz \& Ozdemir, 2006). It is a factor that shows users' willingness to perform a behavior (Ajzen, 1991). According to Teo (2010), using intention to use as a dependent variable has advantages since asking participants about their actual use of E-learning may discourage them to participate in a study. In addition, compared to actual use, behavioral intention to use is a more progressive dependent variable. Therefore, the present study employed intention to use as a dependent variable.

TAM has been widely used around the globe to examine secondary teacher acceptance of e-learning. For instance, De Smet et al. (2012) collected data from 505 Flemish secondary school teacher to understand acceptance of e-learning by secondary school teachers and to investigate the instructional use of e-learning. The study indicated that perceived ease of use of e-learning is the strongest predictor in e-learning acceptance. Another study was conducted by (Alzahrani, 2019) in Saudi Arabia. This study revealed that the TAM model can be used to explain factors influencing secondary school teachers' acceptance of e-learning in context of Saudi Arabia. Stockless (2018) conducted a study in Canada aiming at identifying the factors that influence teachers' intention to use e-learning. This study showed that perceived usefulness is a strong predictor or teachers' intention to use e-learning.

\section{The TAM Variables and Hypotheses}

\section{Experience as an external variable of TAM}

Existing studies have revealed that experience significantly influences users' perceived ease of use (PEU) of E-learning systems (De Smet et al., 2012; Lee et al., 2013; Purnomo \& Lee, 2013). Users who have more experience tend to have a more favorable feeling toward technology ease of use (Lee et al., 2013; Purnomo \& Lee, 2013). Regarding perceived usefulness (PU), prior studies have revealed a significant effect of users' experience on their PU of E-learning (Lee et al., 2013; Martin, 2012; Purnomo \& Lee, 2013; Rezaei, Mohammadi, Asadi, \& Kalantary, 2008). In terms of behavioral intention, previous studies have also shown that users' computer experience affects their intention to use E-learning technology (De Smet et al., 2012; 
Premchaiswadi, Porouhan, \& Premchaiswadi, 2012; Williams \& Williams, 2010). In this current study, we used teachers' E-learning experience during their in-service professional development program (hereafter XIT) as an external variable of TAM. Hence, we proposed the following hypotheses:

H1. XIT significantly affects PU of E-learning in teaching of mathematics

H2. XIT significantly affects PEU of E-learning in teaching of mathematics

H3. XIT significantly affects BI to use E-learning in teaching of mathematics

\section{Perceived ease of use (PEU)}

In the context of E-learning, PEU is defined as the extent to which a user believes that using E-learning will be free of effort (Lin, Chen, \& Fang, 2010). It has an effect on PU (Davis, 1989) as well as on AT (Chang, Yan, \& Tseng, 2012; Wu \& Zhang, 2014). Furthermore, numerous studies have validated the significance of PEU as one of the main predictors of attitude toward acceptance of technology (Briz-Ponce \& García-Peñalvo, 2015; Calisir, Altin Gumussoy, Bayraktaroglu, \& Karaali, 2014; Hamid, Razak, Bakar, \& Abdullah, 2016). In this study, we looked at teachers' PEU of E-learning in teaching. Hence, the following hypotheses were proposed.

H4. PEU significantly affects PU of E-learning in teaching of mathematics

H5. PEU significantly affects AT toward using E-learning in teaching of mathematics

H6. PEU significantly affects BI to use E-learning in teaching of mathematics

\section{Perceived usefulness (PU)}

Lin et al. (2010) define PU of E-learning as the extent to which a user believes that E-learning can help them to achieve learning objectives. Previous studies showed that PU is one of the main factors that influences users' attitude toward technology (Chang et al., 2012; Hamid et al., 2016; Hess, McNab, \& Basoglu, 2014; Mou, Shin, \& Cohen, 2017). Furthermore, PU also has a direct and an indirect effect on behavioral intention (Teo, 2010; Wong, 2015). Hence, regarding the previous studies, we proposed two hypotheses:

H7. PU significantly affects BI to use E-learning in teaching of mathematics

H8. PU significantly affects AT toward using E-learning in teaching of mathematics

\section{Attitude toward using (AT)}

Kaplan (1972) defined attitude as a tendency in response to an event in a favorable or an unfavorable way. Many studies on E-learning acceptance have showed that attitude becomes a significant predictor of $\mathrm{BI}$ to use E-learning (e.g., Cheung \& Vogel, 2013; Tosuntaş, Karadağ, \& Orhan, 2015). The connection between AT and $\mathrm{BI}$ implied that users tend to follow certain behaviors based on their positive attitude toward them (Keong, Albadry, \& Raad, 2014). Furthermore, attitude toward technology fully mediates effects on behavioral intention. Therefore, we proposed hypothesis 9.

H9. AT significantly affects BI to use E-learning in teaching of mathematics

\section{Behavioral intention (BI)}

There are two outcome variables of the TAM model, namely behavioral intention (BI) and actual use (AU). BI is defined as behavioral tendency to keep using technology in the future; therefore, it determines acceptance of technology (Alharbi \& Drew, 2014). Previous studies have confirmed that BI positively affects AU. Furthermore, earlier studies showed that BI is influenced by PU (Tarhini, Elyas, Akour, \& Al-Salti, 2016), PEU (Tarhini et al., 2016; Wu \& Zhang, 2014), and AT (Hussein, 2017; Letchumanan \& Tarmizi, 2011; Sharma \& Chandel, 2013; Taat \& Francis, 2019). As mentioned previously, in this study, BI is a dependent variable. Therefore, we incorporated intention to use E-learning as an outcome of our research model as presented in Figure 2. 


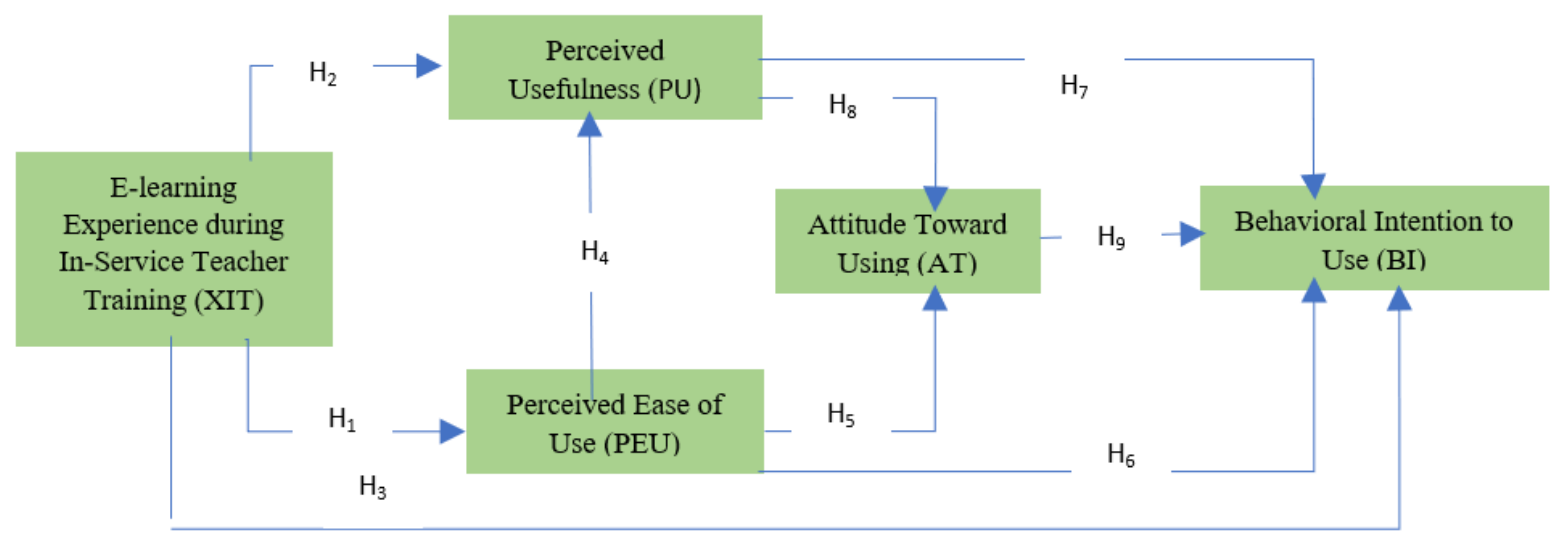

Figure 2. The structural model of the hypotheses

\section{RESEARCH MODEL}

The discussion presented previously suggests that E-learning experience is a significant factor that strongly affects PEU, PU and $\mathrm{BI}$ in the E-learning context. As mentioned earlier, in the present study, teachers' $\mathrm{E}-$ learning experience during their in-service training was included as an external factor of the TAM model, as shown in Figure 2.

\section{METHOD}

\section{Design of the Study}

We employed a quantitative approach with a cross-sectional questionnaire (Fraenkel, Wallen, \& Hyun, 2011). A quantitative method is able to provide reliable, valid, objective and generalizable findings, and questionnaires can be distributed to many participants. Furthermore, according to Fraenkel et al. (2011), a quantitative method enables generalizations about the whole population. In addition, a quantitative study relies on hypothesis testing, where clear guidelines and objectives can be followed (Shank \& Brown, 2013). In this research, we tested hypotheses to predict secondary school teachers' behavioral intention to use Elearning in their teaching of mathematics.

\section{Instrument Design and Development}

According to Lew, Lau, and Leow (2019), questionnaire is a widely used method in studies of technology acceptance. It allows researchers to collect data that reflect opinions and behaviors of a group of people (Queirós, Faria, \& Almeida, 2017). Therefore, a questionnaire of 21 Likert-scale items was developed. The question items were designed based on the five constructs (PU, PEU, AT, BI, and XIT) of the model. We labelled the five scale questions as 'Strongly Disagree', 'Disagree', 'Neutral', 'Agree, and 'Strongly Agree', and they were ranged from 1 to 5 , respectively.

In order to assess content validity of the constructs, the questionnaire was reviewed by two experts. The instrument was examined through content validity index. The experts were requested to examine if the items covered all related aspect. The results showed that the average score of the item above the threshold value which is 0.800 (Halek, Holle, \& Bartholomeyczik, 2017). Furthermore, all items values were above the threshold values of 0.780 . Furthermore, a pilot test was carried out with eight selected teachers. After the teachers completed the questionnaire, they were interviewed to make sure that they understood the questions and that questionnaire items made sense for them. The questions were then revised according to comments from the interviewees. 
Table 1. Demographic profile of respondents

\begin{tabular}{lccc}
\hline & Demographic Background & Number of Participants & Percentage \\
\hline Gender & Male & 83 & $51.6 \%$ \\
& Female & 78 & $48.4 \%$ \\
\hline Level of Education & Undergraduate Degree & 141 & $87.6 \%$ \\
& Postgraduate Degree & 20 & $12.4 \%$ \\
\hline Teaching Experience & $0-5$ Years & 32 & $19.9 \%$ \\
& $6-10$ Years & 58 & $36.0 \%$ \\
& $11-15$ Years & 48 & $29.8 \%$ \\
& $16-20$ Years & 14 & $8.7 \%$ \\
\hline Teacher Certification & More than 20 Years & 9 & $5.6 \%$ \\
& Yes & 117 & $72.7 \%$
\end{tabular}

\section{Research Participants}

The respondents of this study were secondary school mathematics teachers in Indonesia who participated in an in-service professional development program offered by the government through an online learning system. It took six months for participants to complete the training. The contents of training were contents of mathematics and the subject specific pedagogy. The training has been offered since 2018 and is available at 42 Higher Education Institutions (HEIs) across the nation.

The study was conducted in one of the assigned HEls that provided the training for 1200 teachers in 2019 consisting of five cohorts. The institution is a public university located in northern end of Sumatra island, Indonesia. This university is ranked in the top 20 Universities in the country. We chose this university as the teachers who participated in the teacher professional development were not only from the province where the university located but also from other provinces in Indonesia. The participants of the training program were enrolled by the ministry of education and culture into the university.

Random sampling was employed for the selection of respondents. Participants' demographic information is highlighted in Table 1.

A total of 161 secondary school mathematics teachers in Indonesia participated in this study by completing the questionnaire. Respondents consisted of 83 (51.6\%) male and 78 (48.4\%) female teachers. The majority of respondents had an undergraduate degree (87.6\%), while the remaining had a postgraduate degree $(12.4 \%)$. Majority of the participants had more than six years of teaching experience as well as were being certificated by the Indonesian government.

\section{Data Collection}

Prior to data collection, we acquired ethical approval for this study. Subsequently, we conducted an online questionnaire because it could be easily administered and accessible with various devices (See., Fraenkel et al., 2011). The majority of participants were contacted through WhatsApp and email. We administered the online questionnaire in Google Form by sending a link to participants and keeping the questionnaire active for four weeks.

\section{Data Analysis}

Structural Equation Modelling (SEM) was utilized. Partial Least Squares SEM (PLS-SEM) was appropriate for the study in order to predict teachers' behavioral intention to use E-learning for teaching of mathematics. Therefore, SMART PLS 3.0 was run to examine Confirmatory Factor Analysis (CFA) and to assess the reliability, validity, internal consistency of the model. A structural model was developed, and the hypotheses were confirmed. 


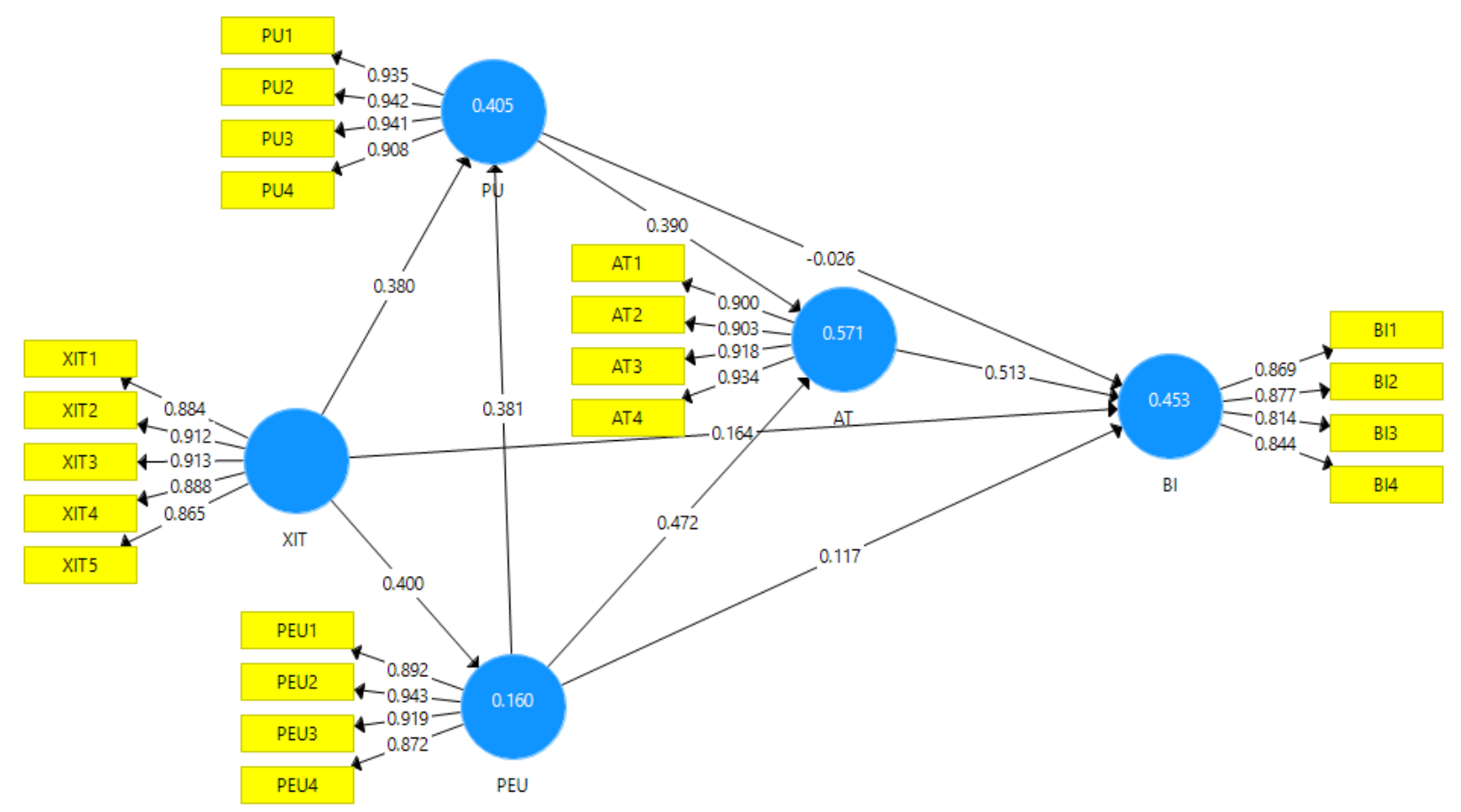

Figure 3. Structural model and path coefficients

\section{RESULTS}

\section{Factor Analysis}

Five constructs, namely, XIT, PEU, PU, AT, and BI had been revealed for assessing factor analysis. We present the structural model and its path coefficients in Figure 3.

To assess the accuracy of the structural model, we measured $R^{2}$ values. The structural model shows that $R^{2}$ is 0.453 for $\mathrm{BI}$ as an endogenous construct. It implies that the four exogenous constructs (XIT, PEU, PU and AT) moderately explain $45.3 \%$ of the variance in $\mathrm{Cl}$ (Hair, Hult, Ringle, \& Sarstedt, 2017). The inner model suggests that $A T$ is the strongest predictor that significantly affects $B I(\beta=0.513$, $t$-value $=5.880)$, followed by XIT $(\beta=0.164$, $t$-value $=2.267)$. The results indicate that AT and XIT have a strong positive relationship with BI by having t-value $>1.645$ for a significance level of $5 \%(\alpha=0.05)$ (Hair et al., 2017).

Regarding AT as an endogenous construct, the model shows that $R^{2}$ is 0.571 for AT. This indicates that the two constructs (PEU and PU) moderately explain $57.1 \%$ of the variance in AT. The model also suggests that PEU is the strongest factor that significantly affects $A T(\beta=0.472$, $t$-value $=6.217)$, followed by $P U(\beta=0.390$, $t$-value $=5.771)$. Having those $t$ values, it indicates that PEU and PU have a strong positive relationship with AT.

In addition, in terms of PU, the results reveal that $\mathrm{R}^{2}$ is 0.405 for $\mathrm{PU}$. This implies the two constructs (PEU and XIT) moderately explain $40.5 \%$ of the variance in PU. The model shows that PEU is the strongest predictor that significantly affects $P U(\beta=0.381$, $t$-value $=5.369)$, followed by XIT $(\beta=0.380, t$-value $=5.971)$. These results indicate that XIT and PEU have strong positive relations.

Furthermore, three assessment criteria namely, convergent validity, internal consistency reliability, and discriminant validity were employed to assess the theoretical model. Regarding convergent validity, we measured the outer loadings of the indicators and the Averaged Variance Extracted (AVE) (Hair et al., 2017). Loading values equal to or larger than 0.7 indicate adequate convergent validity (Hair et al., 2017). In terms of Composite Reliability (CR), which measures internal consistency reliability, CR value above 0.7 is regarded as adequate. Table 3 presents loading values, CR and AVE of the constructs. 
Table 2. Convergent validity and composite reliability

\begin{tabular}{|c|c|c|c|c|}
\hline Construct & Items & Loadings & $\mathrm{CR}$ & AVE \\
\hline \multirow[t]{4}{*}{$\mathrm{PU}$} & PU1 & 0.935 & 0.900 & 0.867 \\
\hline & PU2 & 0.942 & & \\
\hline & PU3 & 0.941 & & \\
\hline & PU4 & 0.908 & & \\
\hline \multirow[t]{4}{*}{ PEU } & PEU1 & 0.892 & 0.755 & 0.614 \\
\hline & PEU2 & 0.943 & & \\
\hline & PEU3 & 0.919 & & \\
\hline & PEU4 & 0.872 & & \\
\hline \multirow[t]{4}{*}{ AT } & AT1 & 0.900 & 0.889 & 0.835 \\
\hline & AT2 & 0.903 & & \\
\hline & AT3 & 0.918 & & \\
\hline & AT4 & 0.934 & & \\
\hline \multirow[t]{4}{*}{$\overline{B I}$} & BI1 & 0.869 & 0.847 & 0.725 \\
\hline & $\mathrm{B} 12$ & 0.877 & & \\
\hline & $\mathrm{BI} 3$ & 0.814 & & \\
\hline & $\mathrm{B} 14$ & 0.844 & & \\
\hline \multirow[t]{5}{*}{$\overline{X I T}$} & XIT1 & 0.884 & 0.951 & 0.797 \\
\hline & XIT 2 & 0.912 & & \\
\hline & XIT 3 & 0.913 & & \\
\hline & XIT 4 & 0.888 & & \\
\hline & XIT 5 & 0.865 & & \\
\hline
\end{tabular}

Table 3. Discriminant validity (Fornell-Lacker criterion)

\begin{tabular}{lccccc}
\hline & AT & BI & PEU & PU & XIT \\
\hline AT & $\mathbf{0 . 9 1 4}$ & & & & \\
BI & 0.650 & $\mathbf{0 . 8 5 1}$ & & & \\
PEU & 0.681 & 0.518 & $\mathbf{0 . 9 0 7}$ & 0.932 & 0.892 \\
PU & 0.641 & 0.453 & 0.532 & 0.532 & 0.400 \\
XIT & 0.449 & 0.428 & 0.932 & \\
\hline
\end{tabular}

Table 2 shows that all indicators have loadings over 0.7 , which is considered a high convergent validity and acceptable (Hair et al., 2017). It implies that all indicators have exceeded the threshold value; therefore, indicator reliability was satisfactory. Furthermore, values of AVEs satisfy the threshold level of AVE ( $\geq 0.5)$, indicating that convergent validity is confirmed (Hair et al., 2017). Therefore, we can conclude that the constructs meet reliability and convergent validity requirements.

Furthermore, we employed cross-loading criterion (Hair et al., 2017) and Heterotrait-Monotrait Ratio of Correlation (HTMT) (Henseler, Ringle, \& Sarstedt, 2015) to assess discriminant validity. Constructs exhibit threshold of discriminant validity when the square roots of AVEs are all higher than the value of interconstruct on the same columns and rows (Fornell \& Larcker, 1981). Table 4 shows that all constructs have met the threshold of discriminant validity for AT (0.914), BI (0.851), PEU (0.907), PU (0.932) and XIT (0.892).

Regarding cross-loading criterion, Table 4 shows that the loading values of all indicators on the constructs were all higher than the loading values of other constructs. This indicates that the indicators of the constructs are interchangeable.

As mentioned earlier, we measured Heterotrait-Monotrait Ratio of Correlation (HTMT) (Henseler (2010) as an alternative approach to assess discriminant validity. HTMT was employed to confirm every construct is distinct from one another. As shown in Table 5, there was no confidence interval of HTMT for the paths with the value of 1 , which indicates the constructs have sufficient discriminate validity (See., Henseler, 2010). Finally, we can conclude that Fornell-Larcker criterion, cross-loading criterion and HTMT revealed that the constructs exhibit sufficient discriminant validity. 
Table 4. Discriminant validity (cross-loading criterion)

\begin{tabular}{llllll}
\hline & AT & BI & PEU & PU & XIT \\
\hline AT1 & $\mathbf{0 . 9 0 0 2}$ & 0.5629 & 0.6434 & 0.6390 & 0.4030 \\
AT2 & $\mathbf{0 . 9 0 2 9}$ & 0.5771 & 0.6083 & 0.5408 & 0.4179 \\
AT3 & $\mathbf{0 . 9 1 7 6}$ & 0.6430 & 0.6193 & 0.5499 & 0.3764 \\
AT4 & $\mathbf{0 . 9 3 3 7}$ & 0.5909 & 0.6170 & 0.6127 & 0.4451 \\
BI1 & 0.6259 & $\mathbf{0 . 8 6 8 8}$ & 0.4363 & 0.4446 & 0.4082 \\
BI2 & 0.5751 & $\mathbf{0 . 8 7 7 2}$ & 0.4593 & 0.4070 & 0.4187 \\
BI3 & 0.4766 & $\mathbf{0 . 8 1 4 0}$ & 0.4172 & 0.3035 & 0.2843 \\
BI4 & 0.5187 & $\mathbf{0 . 8 4 4 3}$ & 0.4509 & 0.3709 & 0.3283 \\
PEU1 & 0.5414 & 0.4905 & $\mathbf{0 . 8 9 0 5}$ & 0.4913 & 0.3671 \\
PEU2 & 0.6053 & 0.4353 & $\mathbf{0 . 9 4 2 6}$ & 0.4761 & 0.3431 \\
PEU3 & 0.5917 & 0.4641 & $\mathbf{0 . 9 1 8 8}$ & 0.4650 & 0.3263 \\
PEU4 & 0.7119 & 0.4826 & $\mathbf{0 . 8 7 4 2}$ & 0.4941 & 0.4050 \\
PU1 & 0.5619 & 0.4150 & 0.5003 & $\mathbf{0 . 9 3 4 4}$ & 0.4975 \\
PU2 & 0.6130 & 0.4455 & 0.5339 & $\mathbf{0 . 9 4 1 1}$ & 0.4744 \\
PU3 & 0.5953 & 0.4098 & 0.4688 & $\mathbf{0 . 9 4 1 2}$ & 0.4930 \\
PU4 & 0.6173 & 0.4164 & 0.4804 & $\mathbf{0 . 9 0 9 0}$ & 0.5181 \\
XIT1 & 0.3716 & 0.3888 & 0.3763 & 0.4219 & $\mathbf{0 . 8 8 3 5}$ \\
XIT2 & 0.4250 & 0.3752 & 0.3637 & 0.5016 & $\mathbf{0 . 9 1 2 0}$ \\
XIT3 & 0.4469 & 0.3965 & 0.3840 & 0.4956 & $\mathbf{0 . 9 1 3 4}$ \\
XIT4 & 0.3589 & 0.3972 & 0.3253 & 0.4962 & $\mathbf{0 . 8 8 7 6}$ \\
XIT5 & 0.3992 & 0.3503 & 0.3342 & 0.4572 & $\mathbf{0 . 8 6 4 5}$ \\
\hline & & & &
\end{tabular}

Table 5. Discriminant validity (HTMT)

\begin{tabular}{cccccc}
\hline & AT & BI & PEU & PU & XIT \\
\hline AT & - & & & & \\
BI & 0.713 & - & & & \\
PEU & 0.726 & 0.573 & 0.566 & - & - \\
PU & 0.689 & 0.492 & 0.426 & 0.564 & - \\
XIT & .480 & 0.467 & 0.56 & \\
\hline
\end{tabular}

Table 6. Lateral collinearity assessment and hypothesis testing

\begin{tabular}{|c|c|c|c|c|c|c|c|c|}
\hline Hypothesis & Relationship & VIF & Std Error & Std Beta & t-value & P Value & $\mathrm{R}^{2}$ & $F^{2}$ \\
\hline $\mathrm{H} 1$ & $\mathrm{XIT} \rightarrow \mathrm{PEU}$ & 1.000 & 0.069 & 0.400 & 5.765 & 0.000 & 0.160 & 0.190 \\
\hline $\mathrm{H} 2$ & $\mathrm{XIT} \rightarrow \mathrm{PU}$ & 1.190 & 0.064 & 0.380 & 5.971 & 0.000 & 0.405 & 0.204 \\
\hline $\mathrm{H} 4$ & $\mathrm{PEU} \rightarrow \mathrm{PU}$ & 1.190 & 0.071 & 0.381 & 5.369 & 0.000 & & 0.205 \\
\hline $\mathrm{H} 5$ & $\mathrm{PEU} \rightarrow \mathrm{AT}$ & 1.396 & 0.076 & 0.472 & 6.217 & 0.000 & 0.571 & 0.372 \\
\hline $\mathrm{H} 8$ & $\mathrm{PU} \rightarrow \mathrm{AT}$ & 1.396 & 0.066 & 0.390 & 5.771 & 0.000 & & 0.254 \\
\hline$\overline{\mathrm{H} 3}$ & $\mathrm{XIT} \rightarrow \mathrm{BI}$ & 1.446 & 0.073 & 0.164 & 2.267 & 0.024 & 0.453 & 0.034 \\
\hline $\mathrm{H} 6$ & $\mathrm{PEU} \rightarrow \mathrm{BI}$ & 1.932 & 0.106 & 0.117 & 1.096 & 0.273 & & 0.013 \\
\hline $\mathrm{H} 7$ & $\mathrm{PU} \rightarrow \mathrm{BI}$ & 1.979 & 0.070 & -0.026 & 0.368 & 0.713 & & 0.001 \\
\hline $\mathrm{H} 9$ & $\mathrm{AT} \rightarrow \mathrm{BI}$ & 2.353 & 0.087 & 0.513 & 5.880 & 0.000 & & 0.204 \\
\hline
\end{tabular}

\section{Hypothesis Testing}

Table 6 presents the results of the assessments of the structural model. First, we addressed the lateral collinearity issue. To assess this, we used the Variance Inflation Factor (VIF). VIF values need to be above 0.2 and below 5.0 (Hair et al., 2017). Table 7 shows that all the inner VIF values for the independent variable are above 0.2 and below 5.0. Therefore, we conclude that in this study lateral multicollinearity is satisfactory.

Second, $t$-values for all paths were measured using the bootstrapping function of SMART PLS 3 to examine the significance level. Furthermore, we used Cohen's $f^{2}$ to evaluate the effect size of AT and XIT on BI (Cohen, 2013). Overall, Table 6 shows that seven out of nine relationships are identified as having t-value $>1.645$. Therefore, they are significant at a 0.05 level of significance. 
Table 7. Summary of hypotheses testing

\begin{tabular}{|c|c|c|c|c|}
\hline Hypothesis & Effects & Direction & Path Coefficient & Conclusion \\
\hline $\mathrm{H} 1$ & $\mathrm{XIT} \rightarrow \mathrm{PEU}$ & Positive & .400 & Supported \\
\hline $\mathrm{H} 2$ & $\mathrm{XIT} \rightarrow \mathrm{PU}$ & Positive & .380 & Supported \\
\hline $\mathrm{H} 3$ & $\mathrm{XIT} \rightarrow \mathrm{BI}$ & Positive & .164 & Supported \\
\hline $\mathrm{H} 4$ & $\mathrm{PEU} \rightarrow \mathrm{PU}$ & Positive & .381 & Supported \\
\hline H5 & $\mathrm{PEU} \rightarrow \mathrm{AT}$ & Positive & .472 & Supported \\
\hline H6 & $\mathrm{PEU} \rightarrow \mathrm{BI}$ & Positive & .117 & Not supported \\
\hline $\mathrm{H} 7$ & $\mathrm{PU} \rightarrow \mathrm{BI}$ & Negative & -.026 & Not Supported \\
\hline $\mathrm{H} 8$ & $\mathrm{PU} \rightarrow \mathrm{AT}$ & Positive & .390 & Supported \\
\hline $\mathrm{H9}$ & $\mathrm{AT} \rightarrow \mathrm{BI}$ & Positive & .513 & Supported \\
\hline
\end{tabular}

Experience in using E-learning (XIT) $(\beta=0.400$, t-value $=5.765, p<0.001)$ positively and significantly affects PEU with medium effect size (0.190). Hence, hypothesis 1 is supported. Furthermore, $P E U(\beta=0.381$, $t$-value $=5.369, p<0.001)$ and XIT $(\beta=0.380, t$-value $=5.971, p<0.001)$ positively affects $P U$. Therefore, hypothesis 2 and hypothesis 4 are accepted. In terms of effect size, according to Cohen (2013), $f^{2}$ for PEU (0.205) and XIT (0.204) are regarded as medium effect size.

In terms of attitude toward using E-learning (AT), PEU $(\beta=0.472$, t-value $=6.217, p<0.001)$ and $P U(\beta=0.390$, t-value $=5.771, p<0.001)$ positively affect AT. Therefore, hypothesis 5 and hypothesis 8 are supported. Regarding the effect size of PEU and PU on AT, $\mathrm{f}^{2}$ for PEU (0.372) and PU (0.254) are considered medium effect size.

Regarding behavioral intention to use E-learning (BI), two out of four relationships were found to have $t$ values $>1.645$. Predictors of AT $(\beta=0.513$, t-value $=5.880, p<0.001)$ and XIT $(\beta=0.164$, t-value $=2.267, p<$ $0.05)$ positively relate to BI. Hence, hypothesis 3 and hypothesis 9 are supported. However, predictors of PEU $(\beta=0.117, t$-value $=1.096, p>0.05)$ and $P U(\beta=-0.026, t$-value $=0.368, p>0)$ do not significantly and positively relate to BI. Therefore, hypothesis 6 and hypothesis 7 are rejected. According to Cohen (2013), $\mathrm{f}^{2}$ for AT $(0.204)$ is considered as a moderate effect, while $\mathrm{f}^{2}$ for XIT(0.034) is considered as small effect size. Summary of the results of hypotheses testing is presented in Table 7.

\section{DISCUSSION}

The main aim of this study is to examine factors that affect secondary school mathematics teachers' behavioral intention (BI) to use E-learning in their teaching. This study is distinct from other studies because it was conducted in the context of COVID-19 pandemic and it investigated teachers who experience using Elearning for their professional development. Hence, it is necessary to examine teachers' behavioral intention to advance our understanding of the factors that play a significant role in teachers' use of E-learning in their teaching, particularly for teachers who have experience in using E-learning for their professional development. To achieve this aim, TAM model (Davis, 1986) was adopted with an addition of an external factor of teacher experience in using E-learning during in-service professional development. The hypotheses related to the directional link between TAM scales and the external factor were examined. Results of this study show three crucial points of discussion.

First, the study suggests that teachers' E-learning experience (XIT) has a significant direct effect on their perceived ease of use (PEU) and perceived usefulness (PU) of E-learning. This finding is consistent with existing studies (Lau \& Woods, 2008; Martin, 2012; Pituch \& Lee, 2006; Rezaei et al., 2008; Williams \& Williams, 2010), confirming the significant effect of experience on users' PEU. Previous studies revealed that users' experience had a significant effect on their PU of E-learning (Lee et al., 2013; Martin, 2012; Rezaei et al., 2008). Teachers, throughout their careers, had many chances to participate in online professional development to develop their content knowledge and pedagogical knowledge. For instance, in the Indonesian context, for the last two years the government provided in-service teachers online certification programs. This study shows that such training, to some extent, has affected teachers' PU and PEU of elearning for their teaching. Therefore, this study indicated that teacher online professional development has 
positive impact on not only teacher knowledge development but also on their acceptance of e-learning for their instructional purpose. The effectiveness of online teacher professional development has received much intention from research around the world. Therefore, it enriches the literature in terms of advancing our understanding of teachers' perceived ease of use and perceived usefulness of e-learning for their instruction.

Second, regarding attitude of use (AT), the results show that PEU $(\beta=0.472$, t-value $=6.217, p<0.001)$ and $P U(\beta=0.390$, $t$-value $=5.771, p<0.001)$ appear to be strong predictors of AT. Previous studies have shown the importance of PU and PEU for attitude toward using E-learning (Hamid et al., 2016; Hess et al., 2014; Mou et al., 2017). Therefore, this finding is consistent with our hypothesis that teachers' PEU and PU of Elearning positively and significantly affect their attitude toward using E-learning.

Third, regarding teachers' behavioral intention to use E-learning (BI), the results suggest that AT $(\beta=0.513, t-$ value $=5.880, p<0.001)$ is the strongest predictor of $B$, followed by XIT $(\beta=0.164$, t-value $=2.267, p<0.05)$. Previous studies also have proved the importance of attitude (AT) as an intrinsic motivator for behavioral intention (Hussein, 2017; Letchumanan \& Tarmizi, 2011; Sharma \& Chandel, 2013; Taat \& Francis, 2019). In addition to that, the findings of this study that experience impacts users' intention to use E-learning are in line with findings in previous studies (De Smet et al., 2012; Premchaiswadi et al., 2012; Williams \& Williams, 2010). Another result reveals that PEU $(\beta=0.117, t$-value $=1.096, p>0.05)$ and $P U(\beta=-0.026, t$-value $=0.368$, $p>0)$ are not significantly and positively related to BI. Several past studies showed similar findings that PU (Lew et al., 2019; Park, 2009; Yuen \& Ma, 2008) and PEU (Lew et al., 2019) were non-significant for the prediction of behavioral intention to use E-learning. However, the other previous studies found the opposite, that perceived ease of use (PEU) and perceived usefulness (PU) directly influence intention to use E-learning (Al-Gahtani, 2016; Elkaseh, Wong, \& Fung, 2016; Hsia, Chang, \& Tseng, 2014; Lee, Hsiao, \& Purnomo, 2014; Tarhini et al., 2016; Tarhini, Hone, \& Liu, 2014).

Regarding the context of this study, there are two possible reasons why PU and PEU are not crucial in teachers' behavioral intention to use E-learning in teaching. First, the participants were teachers who had long experience in using E-learning for their online professional development. Lin (2011) found a similar finding that suggests PEU has a more critical impact on intention of less experienced users than more experienced users. These results are consistent with the finding of another study (Castañeda, Muñoz-Leiva, \& Luque, 2007), in the context of intention to use the website, showing that PEU is a more important factor for less experienced users than for more experienced users. Therefore, this indicates that, for experienced teachers, perceived ease of use does not play significant role in their adoption of e-learning for teaching purpose. For experienced teachers, other factors play such as attitude play much more significant role then perceived ease of use does. The reason for this lies in the fact that different individual view e-learning from perspective. For example, in the context of the use of a website, Castañeda et al. (2007) revealed that the experience users are more interested in the outcome of search while new users evaluate the website the novelty of the site. In other words, Castañeda et al. (2007) argued that experienced users are influenced by extrinsic motivation while new users are influenced by intrinsic motivations such as perceived ease of use. Second, according to Davis (1993), perceived usefulness is the expected overall positive impact of system use on job outcome while PEU is the extent to which a user thinks that using a system will be free of effort. In the context of this study, the data collection took place during the COVID-19 pandemic when school closure left students and teachers dependent on E-learning. In such circumstances, when the teachers do not have other options for remote teaching, perceived usefulness and perceived ease of use of E-learning might become less important factors in teachers' decisions to use or not to use E-learning.

For that reason, this study leaves room for debate on this issue and future work is necessary to explore it.

The findings of this study indicate that having experience in using E-learning for teacher professional development does not guarantee that teachers will use E-learning in their teaching. For this type of teacher, attitude is the crucial factor that determines their use of E-learning technology in their instruction. However, having teacher training experience positively affects their perceived usefulness and perceived ease of use of E-learning. Therefore, if schools and policymakers would like to enhance the integration of E-learning in secondary schools, particularly during the pandemic, along with providing training for teachers, much more 
effort is needed to ensure teachers have strong intentions to adopt technology and more importantly to ensure that teachers possess a strong positive attitude toward the E-leaning system.

\section{CONCLUSION}

This study revealed factors that determine teachers' behavioral intention to use E-learning in their mathematics teaching, particularly teachers who have experience in using E-learning for their professional development. The results showed that two out of four exogenous constructs have a positive effect on teachers' behavioral intention to use E-learning, namely attitude toward using, and experience in using Elearning. Teachers' attitudes toward using E-learning plays the most significant role in their behavioral intention. In addition, E-learning experience positively and significantly affects teachers' attitude toward Elearning. This study suggested that, for experienced teachers, perceived ease of use and perceived usefulness did not have a significant positive impact on teacher behavioral intention.

There are several limitations of this study that need to be addressed in future studies. First, the participants of this study were teachers who participated in an online teacher professional development program in one $\mathrm{HEl}$ assigned by the Indonesian government. This condition may influence the generalizability of the finding of this study. Therefore, further research is needed to validate this model in other HEls. Second, the present study revealed that perceived usefulness (PU) and perceived ease of use (PEU) did not have a significant positive effect on teachers' behavioral intention to use E-learning. Thus, future research should aim to explore this issue in the context of teachers who experienced using E-learning for their professional development. Finally, this study has one external factor, namely E-learning experience. However, additional external factors of behavioral intention may also exist. As a result, future work should consider other external variables, such as school facilities and support for the integration of E-learning.

\section{ACKNOWLEDGEMENTS}

We would like to thank all participants involved in this study. We would also like to thank Realistic Mathematics Education Research Centre of Syiah Kuala University.

\section{REFERENCES}

Abbad, M. M., Morris, D., \& De Nahlik, C. (2009). Looking under the bonnet: Factors affecting student adoption of e-learning systems in Jordan. The International Review of Research in Open and Distributed Learning, 10(2). https://doi.org/10.19173/irrodl.v10i2.596

Abdullah, F., \& Ward, R. (2016). Developing a General Extended Technology Acceptance Model for E-Learning (GETAMEL) by analysing commonly used external factors. Computers in human behavior, 56, 238-256. https://doi.org/10.1016/j.chb.2015.11.036

Ajibade, P. (2018). Technology Acceptance Model Limitations and Criticisms: Exploring the Practical Applications and Use in Technology-related Studies, Mixed-method, and Qualitative Researches. Library Philosophy and Practice.

Ajzen, I. (1991). The theory of planned behavior. Organizational behavior and human decision processes, $50(2), 179-211$.

Al-Gahtani, S. S. (2016). Empirical investigation of e-learning acceptance and assimilation: A structural equation model. Applied Computing and Informatics, 12(1), 27-50. https://doi.org/10.1016/j.aci.2014.09.001

Alharbi, S., \& Drew, S. (2014). Using the technology acceptance model in understanding academics' behavioural intention to use learning management systems. International Journal of Advanced Computer Science and Applications, 5(1), 143-155. https://doi.org/10.14569/ijacsa.2014.050120 
Alzahrani, A. M. (2019). Factors that influence secondary school teachers' acceptance of e-learning technologies in teaching in the kingdom of Saudi Arabia. Journal of Research in Curriculum Instruction and Educational Technology, 5(2), 175-196.

Briz-Ponce, L., \& García-Peñalvo, F. J. (2015). An empirical assessment of a technology acceptance model for apps in medical education. Journal of medical systems, 39(11), 176. https://doi.org/10.1007/s10916015-0352-x

Calisir, F., Altin Gumussoy, C., Bayraktaroglu, A. E., \& Karaali, D. (2014). Predicting the intention to use a web - based learning system: Perceived content quality, anxiety, perceived system quality, image, and the technology acceptance model. Human Factors and Ergonomics in Manufacturing \& Service Industries, 24(5), 515-531. https://doi.org/10.1002/hfm.20548

Castañeda, J. A., Muñoz-Leiva, F., \& Luque, T. (2007). Web Acceptance Model (WAM): Moderating effects of user experience. Information \& management, 44(4), 384-396. https://doi.org/10.1016/j.im.2007.02. 003

Chang, C.-C., Yan, C.-F., \& Tseng, J.-S. (2012). Perceived convenience in an extended technology acceptance model: Mobile technology and English learning for college students. Australasian Journal of Educational Technology, 28(5). https://doi.org/10.14742/ajet.818

Chang, C.-T., Hajiyev, J., \& Su, C.-R. (2017). Examining the students' behavioral intention to use e-learning in Azerbaijan? The general extended technology acceptance model for e-learning approach. Computers \& Education, 111, 128-143. https://doi.org/10.1016/j.compedu.2017.04.010

Cheung, R., \& Vogel, D. (2013). Predicting user acceptance of collaborative technologies: An extension of the technology acceptance model for e-learning. Computers \& Education, 63, 160-175. https://doi.org/10.1016/j.compedu.2012.12.003

Chuttur, M. Y. (2009). Overview of the technology acceptance model: Origins, developments and future directions. Working Papers on Information Systems, 9(37), 9-37.

Cigdem, H., \& Topcu, A. (2015). Predictors of instructors' behavioral intention to use learning management system: A Turkish vocational college example. Computers in human behavior, 52, 22-28. https://doi.org/10.1016/j.chb.2015.05.049

Cohen, J. (2013). Statistical power analysis for the behavioral sciences: Academic press. https://doi.org/10.4324/9780203771587

Davis, F. D. (1989). Perceived usefulness, perceived ease of use, and user acceptance of information technology. MIS quarterly, 319-340. https://doi.org/10.2307/249008

Davis, F. D. (1993). User acceptance of information technology: system characteristics, user perceptions and behavioral impacts. International journal of man-machine studies, 38(3), 475-487. https://doi.org/10.1006/imms.1993.1022

Davis. (1986). A technology acceptance model for empirically testing new end-user information systems: Theory and results. Massachusetts Institute of Technology.

De Smet, C., Bourgonjon, J., De Wever, B., Schellens, T., \& Valcke, M. (2012). Researching instructional use and the technology acceptation of learning management systems by secondary school teachers. Computers \& Education, 58(2), 688-696. https://doi.org/10.1016/j.compedu.2011.09.013

Elkaseh, A. M., Wong, K. W., \& Fung, C. C. (2016). Perceived ease of use and perceived usefulness of social media for e-learning in Libyan higher education: A structural equation modeling analysis. International Journal of Information and Education Technology, 6(3), 192. https://doi.org/10.7763/ijiet.2016.v6.683 
Fishbein, M. A., \& Ajzen, I. (1975). Belief, attitude, intention and behaviour: An introduction to theory and research. Reading, MA: Addison-Wesley.

Fornell, C., \& Larcker, D. F. (1981). Evaluating structural equation models with unobservable variables and measurement error. Journal of marketing research, 18(1), 39-50. https://doi.org/10.1177/002224378101800104

Fraenkel, Wallen, N. E., \& Hyun, H. H. (2011). How to design and evaluate research in education: New York: McGraw-Hill Humanities/Social Sciences/Languages.

Hair, J. F., Hult, G. T. M., Ringle, C., \& Sarstedt, M. (2017). A primer on partial least squares structural equation modeling (PLS-SEM): Sage publications. https://doi.org/10.15358/9783800653614

Halek, M., Holle, D., \& Bartholomeyczik, S. (2017). Development and evaluation of the content validity, practicability and feasibility of the Innovative dementia-oriented Assessment system for challenging behaviour in residents with dementia. BMC health services research, 17(1), 554. https://doi.org/10.1186/s12913-017-2469-8

Hamid, A. A., Razak, F. Z. A., Bakar, A. A., \& Abdullah, W. S. W. (2016). The effects of perceived usefulness and perceived ease of use on continuance intention to use e-government. Procedia Economics and Finance, 35(2016), 644-649. https://doi.org/10.1016/s2212-5671(16)00079-4

Henseler, J. (2010). On the convergence of the partial least squares path modeling algorithm. Computational statistics, 25(1), 107-120. https://doi.org/10.1007/s00180-009-0164-x

Henseler, J., Ringle, C. M., \& Sarstedt, M. (2015). A new criterion for assessing discriminant validity in variance-based structural equation modeling. Journal of the academy of marketing science, 43(1), 115135. https://doi.org/10.1007/s11747-014-0403-8

Hess, T. J., McNab, A. L., \& Basoglu, K. A. (2014). Reliability generalization of perceived ease of use, perceived usefulness, and behavioral intentions. MIS quarterly, 38(1), 1-28. https://doi.org/10.25300/misq/2014/38.1.01

Hsia, J.-W., Chang, C.-C., \& Tseng, A.-H. (2014). Effects of individuals' locus of control and computer selfefficacy on their e-learning acceptance in high-tech companies. Behaviour \& Information Technology, 33(1), 51-64. https://doi.org/10.1080/0144929x.2012.702284

Hussein, Z. (2017). Leading to intention: The role of attitude in relation to technology acceptance model in elearning. Procedia Computer Science, 105, 159-164. https://doi.org/10.1016/j.procs.2017.01.196

Kaplan, K. J. (1972). On the ambivalence-indifference problem in attitude theory and measurement: A suggested modification of the semantic differential technique. Psychological bulletin, 77(5), 361. https://doi.org/10.1037/h0032590

Keong, Y. C., Albadry, O., \& Raad, W. (2014). Behavioral intention of EFL teachers to apply e-learning. Journal of Applied Sciences, 14(20), 2561-2569. https://doi.org/10.3923/jas.2014.2561.2569

Kiraz, E., \& Ozdemir, D. (2006). The relationship between educational ideologies and technology acceptance in pre-service teachers. Journal of Educational Technology \& Society, 9(2), 152-165.

Lau, S.-H., \& Woods, P. C. (2008). An empirical study of learning object acceptance in multimedia learning environment. Communications of the IBIMA, 5(1), 1-6.

Lee, Y.-H., Hsiao, C., \& Purnomo, S. H. (2014). An empirical examination of individual and system characteristics on enhancing e-learning acceptance. Australasian Journal of Educational Technology, 30(5). https://doi.org/10.14742/ajet.381 
Lee, Y.-H., Hsieh, Y.-C., \& Chen, Y.-H. (2013). An investigation of employees' use of e-learning systems: applying the technology acceptance model. Behaviour \& Information Technology, 32(2), 173-189. https://doi.org/10.1080/0144929x.2011.577190

Lee, Y.-H., Hsieh, Y.-C., \& Ma, C.-Y. (2011). A model of organizational employees'e-learning systems acceptance. Knowledge-based systems, 24(3), 355-366. https://doi.org/10.1016/j.knosys.2010.09.005

Letchumanan, M., \& Tarmizi, R. (2011). Assessing the intention to use e - book among engineering undergraduates in Universiti Putra Malaysia, Malaysia. Library Hi Tech, 29(3), 512-528. https://doi.org/10.1108/07378831111174459

Lew, S.-L., Lau, S.-H., \& Leow, M.-C. (2019). Usability factors predicting continuance of intention to use cloud e-learning application. Heliyon, 5(6), e01788. https://doi.org/10.1016/j.heliyon.2019.e01788

Lin, K.-M. (2011). e-Learning continuance intention: Moderating effects of user e-learning experience. Computers \& Education, 56(2), 515-526. https://doi.org/10.1016/j.compedu.2010.09.017

Lin, K.-M., Chen, N.-S., \& Fang, K. (2010). Understanding e-learning continuance intention: a negative critical incidents perspective. Behaviour \& Information Technology, 30(1), 77-89. https://doi.org/10.1080/01449291003752948

Mailizar, Almanthari, A., Maulina, S., \& Bruce, S. (2020). Secondary School Mathematics Teachers' Views on E-learning Implementation Barriers during the COVID-19 Pandemic: The Case of Indonesia. Eurasia Journal of Mathematics, Science and Technology Education, 16(7), 1860. https://doi.org/10.29333/ejmste/8240

Mailizar, Samingan, Rusman, Huda, I., \& Yulisman, H. (2020). Mathematics, Science and Social Science teachers' acceptance of online teacher professional development: Does internet accessibility matter? Journal of Physics: Conf. Series, 1460(2020). https://doi.org/10.1088/1742-6596/1460/1/012103

Martin, R. G. (2012). Factors affecting the usefulness of social networking inE-learning at German University of Technology in Oman. International Journal of e-Education, e-Business, e-Management and eLearning, 2(6), 498. https://doi.org/10.7763/ijeeee.2012.v2.171

Mou, J., Shin, D.-H., \& Cohen, J. (2017). Understanding trust and perceived usefulness in the consumer acceptance of an e-service: a longitudinal investigation. Behaviour \& Information Technology, 36(2), 125-139. https://doi.org/10.1080/0144929x.2016.1203024

Park, S. Y. (2009). An analysis of the technology acceptance model in understanding university students' behavioral intention to use e-learning. Journal of Educational Technology \& Society, 12(3), 150-162.

Pituch, K. A., \& Lee, Y.-k. (2006). The influence of system characteristics on e-learning use. Computers \& Education, 47(2), 222-244. https://doi.org/10.1016/j.compedu.2004.10.007

Premchaiswadi, W., Porouhan, P., \& Premchaiswadi, N. (2012). An empirical study of the key success factors to adopt e-learning in Thailand. Paper presented at the International conference on information society (i-Society 2012).

Purnomo, S. H., \& Lee, Y.-H. (2013). E-learning adoption in the banking workplace in Indonesia: an empirical study. Information Development, 29(2), 138-153. https://doi.org/10.1177/0266666912448258

Queirós, A., Faria, D., \& Almeida, F. (2017). Strengths and limitations of qualitative and quantitative research methods. European Journal of Education Studies, 3(9), 451-457.

Rezaei, M., Mohammadi, H. M., Asadi, A., \& Kalantary, K. (2008). Predicting e-learning application in agricultural higher education using technology acceptance model. Turkish Online Journal of Distance Education, 9(1), 85-95. 
Shank, G., \& Brown, L. (2013). Exploring educational research literacy: Routledge. https://doi.org/10.4324/9780203943786

Sharma, S., \& Chandel, J. (2013). Technology Acceptance Model For The Use Of Learning Through Websites Among Students In Oman. International Arab Journal of E-Technology, 3(1), 44-49.

Stockless, A. (2018). Acceptance of learning management system: The case of secondary school teachers. Education and Information Technologies, 23(3), 1101-1121. https://doi.org/10.1007/s10639-0179654-6

Taat, M. S., \& Francis, A. (2019). Factors Influencing the Students' Acceptance of E-Learning at Teacher Education Institute: An Exploratory Study in Malaysia. The International Journal of Higher Education, 9, 133. https://doi.org/10.5430/ijhe.v9n1p133

Tarhini, A., Elyas, T., Akour, M. A., \& Al-Salti, Z. (2016). Technology, demographic characteristics and elearning acceptance: a conceptual model based on extended technology acceptance model. Higher Education Studies, 6(3), 72-89. https://doi.org/10.5539/hes.v6n3p72

Tarhini, A., Hone, K., \& Liu, X. (2014). The effects of individual differences on e-learning users' behaviour in developing countries: A structural equation model. Computers in human behavior, 41, 153-163. https://doi.org/10.1016/j.chb.2014.09.020

Teo, T. (2010). A path analysis of pre-service teachers' attitudes to computer use: applying and extending the technology acceptance model in an educational context. Interactive Learning Environments, 18(1), 6579. https://doi.org/10.1080/10494820802231327

Tosuntaş, Ş. B., Karadağ, E., \& Orhan, S. (2015). The factors affecting acceptance and use of interactive whiteboard within the scope of FATIH project: A structural equation model based on the Unified Theory of acceptance and use of technology. Computers \& Education, 81, 169-178. https://doi.org/10.1016/j.compedu.2014.10.009

Venkatesh, V., \& Davis, F. D. (2000). A theoretical extension of the technology acceptance model: Four longitudinal field studies. Management science, 46(2), 186-204. https://doi.org/10.1287/mnsc.46.2.186.11926

Venkatesh, V., Morris, M. G., Davis, G. B., \& Davis, F. D. (2003). User acceptance of information technology: Toward a unified view. MIS quarterly, 425-478. https://doi.org/10.2307/30036540

Williams, M., \& Williams, J. (2010). Evaluating a model of business school students' acceptance of web-based course management systems. The International Journal of Management Education, 8(3), 59-70. https://doi.org/10.3794/ijme.83.264

Wong, G. K. (2015). Understanding technology acceptance in pre-service teachers of primary mathematics in Hong Kong. Australasian Journal of Educational Technology, 31(6). https://doi.org/10.14742/ajet.1890

Wu, B., \& Zhang, C. (2014). Empirical study on continuance intentions towards E-Learning 2.0 systems. Behaviour \& Information Technology, 33(10), 1027-1038. https://doi.org/10.1080/0144929X.2014.934291

Yuen, A. H., \& Ma, W. W. (2008). Exploring teacher acceptance of e - learning technology. Asia - Pacific Journal of Teacher Education, 36(3), 229-243. https://doi.org/10.1080/13598660802232779

Correspondence: Mailizar Mailizar, Mathematics Education Department, Universitas Syiah Kuala, Indonesia. E-mail: mailizar@unsyiah.ac.id 